\title{
Costoclavicular Syndrome and MRI Evaluation, Our Experience at Tertiary Care Hospital, SKIMS Srinagar, J\&K
}

\author{
Shahnawaz Mansoor Shah*, Imran Mansoor Shah, Zafar Ahmad Anim, Perveez Ahmad Malik \\ Sher-i-Kashmir Institute of Medical Sciences (SKIMS), Srinagar, India \\ Email: "drnawaz1008@gmail.com
}

Received 4 June 2016; accepted 2 July 2016; published 5 July 2016

Copyright ( 2016 by authors and Scientific Research Publishing Inc.

This work is licensed under the Creative Commons Attribution International License (CC BY).

http://creativecommons.org/licenses/by/4.0/

(c) (i) Open Access

\begin{abstract}
Introduction: Cervical rib is a supernumerary rib springing from one of the cervical vertebrae, usually the seventh. About 1 in 200 people are born with cervical rib. About 1 in 10 people who have a cervical rib develop symptoms of thoracic outlet syndrome (TOS). Aims: The aim of this study was to identify normal and abnormal anatomy of thoracic outlet using MRI in symptomatic costoclavicular compression syndrome and to plan them for surgery thereafter. Methods: This was a prospective hospital based study. All the symptomatic cases of cervical rib syndrome admitted in the department of Cardiovascular and thoracic surgery SKIMS, Srinagar from May 2011 to May 2015 were taken up for the study. Results: A total of 40 cases of symptomatic cervical rib syndrome were reported from May 2011 to May 2015. Mean age of presentation was 26.3. The most prevalent age group was 21 - 30 years $(47 \%)$. Majority of patients were females $(83 \%)$ with male female ratio of $1: 5.67 \%$ had bilateral cervical rib, more in females $(72 \%)$ than males $(40 \%) .97 \%$ had neurogenic thoracic outlet syndrome and $3 \%$ had vascular thoracic outlet syndrome. $35 \%$ of cases with neurogenic thoracic outlet syndrome had subclavian artery compression on MR Angio of thoracic outlet after subjecting them to postural maneuvers. All the patients with subclavian artery compression were subjected to surgery. Conclusion: Costoclavicular compression syndrome affects mainly young females. MR Angio is complementary in finding vascular compression in cases presenting mainly with neurogenic symptoms of thoracic outlet syndrome.
\end{abstract}

\section{Keywords}

Costoclavicular Compression Syndrome, MR Angio, Vascular Thoracic Outlet Syndrome, Neurogenic Thoracic Outlet Syndrome, Subclavian Artery Compression, MRI

\footnotetext{
${ }^{*}$ Corresponding author.
} 


\section{Introduction}

A cervical rib is a supernumerary rib, springing from one of the cervical vertebrae, usually the seventh, rarely the sixth and very rarely the fifth. Galen and Vesalius were the first to describe cervical rib in detail. Cervical ribs are normal in crocodiles. Man has normally twelve pairs of ribs. About 1 in 200 people are born with a cervical rib. About 1 in 10 people who have a cervical rib develop thoracic outlet syndrome [1]. The majority of patients with thoracic outlet syndrome (TOS) fall under symptomatic thoracic outlet syndrome (sTOS) classification [2]. True neurogenic TOS (NTOS) accounts for 1\% of neurogenic cases [3]. Symptoms are much more common in women than men. NTOS is found in $90 \%$ to $97 \%$ of cases. Vascular thoracic outlet syndrome accounts for $5 \%$ to $10 \%$ of all cases of TOS. Most frequent symptoms are coldness, pallor, weakness, early fatigue, pain in upper extremity, swelling of arm and hands and spontaneous rupture of venes in hands and fingers may also occur. Postural vertigo and balance difficulties occur frequently in many TOS cases. Most are affected with recurrent pain that may become permanent or get worse when the arms are elevated. Motor deficit occurs much latter and manifests itself by progressive reduction in strength and muscle atrophy, especially in thenar eminence and in very advanced cases, also in forearm. The diagnosis of TOS is essentially based on history and clinical examination. X ray cervical spine, CT, MRI of the thoracic outlet are useful diagnostic examinations. To analyse radiological investigations for studying anatomy of thoracic outlet in symptomatic cases of thoracic outlet syndrome provides the basis for this study.

\section{Aims}

The aim of the present study is to identify normal and abnormal anatomy of thoracic outlet using MRI in symptomatic cases of cervical rib syndrome.

\section{Methods}

We analyzed all the patients of symptomatic costoclavicular compression syndrome admitted in the department of cardiovascular and thoracic surgery SKIMS, Srinagar during 4 consecutive years from May 2011 to May 2015. Diagnosis was based on results of clinical evaluation using various dynamic maneuvers and special investigations like $\mathrm{x}$ ray cervical spine (AP view), MRI thoracic outlet. While subjecting to MR Angio, $0.6 \mathrm{~mm}$ thick slices were taken and three dimensional reconstructions were also done. Images were obtained using pressure injector and automated trigger. During arterial phase $100 \mathrm{ml}$ of non-ionic contrast (Iohexol) was injected through intravenous cannula of appropriate size (pressure injector and Iohexol was provided by the institution where the study was conducted). After identifying the cause of compression over costoclavicular tunnel, patients were subjected to surgery under general anesthesia. The patients were put in right/left lateral position with shoulder abducted, elbow flexed at 90 degrees and arm rested along the side stand provided with soft cushion. Through the hair line incision, first rib was excised from its anterior end including its periosteum towards the posterior end till its maximum part was removed taking care of axillary contents. This was followed by excision of scalene muscles and costoclavicular ligament. Finally soft and hard part of cervical rib was excised. Wound was closed over suction drain.

Stastistical method: Data is described as mean and percentages. SPSS and Microsoft Excel Software were used for data analysis

\section{Results}

It was observed that majority of the patients were females (83\%). 17\% patients were males with male to female ratio of 1:5. Most of the patients were in the age group 21 to 30 years (47\%) with mean age of 26 years. Mean age for males was 30 and that for females 26. Main symptom of presentation was paresthesia in $70 \%$ patients. Second most common symptom was pain in $63 \%$. On clinical examination, weakness was present in $32 \%$ mainly affecting fingers (57\%), loss of sensation to touch/pain in 32\% mainly affecting little finger and ulnar aspect of hand (42\%), atrophy in 30\% mainly affecting thenar eminence (60\%), gangrene and cyanosis of fingers was present in 3\%, supraclavicular mass in 3\%, ptosis in 3\% and miosis in 7\%. After subjecting to provocation test, upper limb tension test was positive in 93\%, Adson's test in 73\%, hyper abduction test in $23 \%$ patients. $67 \%$ patients had bilateral cervical rib on x ray cervical spine (AP view) followed by left cervical rib in $20 \%$, right cervical rib in 10\%. Elongated C7 transverse process was found in 3\% patients. Most common electrophysiological 
abnormality was deranged ulner nerve conduction velocity. 36\% patients had subclavian artery compression on MR Angio of thoracic outlet, 21\% had right subclavian artery compression and 79\% left subclavian artery compression (Table 1 , Table 2).

\section{Discussion}

A cervical rib is a supernumerary rib springing from one of the cervical vertebrae, usually the seventh. Galen and Vesalius were the first to describe a cervical rib in detail. Cervical ribs are normal in crocodiles. Man has normally twelve pairs of ribs. About 1 in 200 people are born with a cervical rib. About 1 in 10 people who have a cervical rib develop TOS [1]. TOS is a clinical phenomenon resulting from compression of neurovascular structures at the superior aperture of thorax presenting with varying symptoms. The reported incidence of TOS in the general population is approximately $0.3 \%$ to $0.7 \%$ [2] [3]. The affected typically range 25 to 40 years (mean 34.6) and a higher incidence (4:1) has been reported in females [3] [4].

A total of 40 patients were admitted in the department of cardiovascular and thoracic surgery SKIMS, Srinagar in 4 consecutive years. The age of presentation of patients in our study ranged from 17 to 49 years with majority of patients being in the age group 21 - 30 years (47\%). Mean age in our patients was 26 years (mean age for males 30 years and for females 25 years). Majority of patients were females (84\%). Ziyad Yaseen and Aram Baram (2007-2010) reported similar age distribution in their study [5].

TOS is a symptom complex characterized by pain, paresthesia, weakness and discomfort in upper limbs which is aggravated by elevation of arms or by exaggerated movements of the head and neck. In our study $70 \%$ of cases presented with paresthesia affecting mainly fingers 38\%. Second most common symptom was pain (63\%) mainly affecting shoulders (58\%) followed by arms (31.5\%), neck (21\%), forearm (21\%) and fingers (16\%). Weakness was present in 32\% patients affecting mainly fingers in 57\% cases followed by arm (52\%), forearm (21\%) and shoulder (15\%). Atrophy was present in 30\% cases affecting mainly thenar eminence (60\%) followed by Interossei (44\%) hypothenar (38\%), finger (27\%), forearm (27\%), arm (11\%) and shoulder (11\% gangrene and cyanosis of fingers was present in 3\% supraclavicular mass in 3\%, ptosis in 3\% and miosis in $7 \%$. Loss of sensation to touch/pain was present in 32\% patients affecting little finger and ulner aspect of hand in $42 \%$, forearm in $26 \%$, index finger in $26 \%$, arm and thumb in $21 \%$, middle finger and radial side of hand in $10 \%$ patients. These observations are similar to those reported in previous study by Daryll M Baker and Andrew J Lamerton [6] and Bronson S. Ray, Robert Hardy and Herbert Parson [7]. Bronson S. Ray et al. [7] reported meiosis in $7 \%$ of cases and ptosis in $2 \%$ in their study which is comparable to our study. Gangrene and cyanosis of fingers was noted in $12 \%$ cases which is higher than our study (3\%). This can be explained by smaller sample size of our study. Ziyad Yaseen and Aram Baram (2007-2010) observed similar results in their study [8].

Neurogenic TOS comprises over $90 \%$ of all TOS while arterial TOS (ATOS) less than $1 \%$. Although the incidence in any one medical Centre is influenced by referral pattern, ATOS is the least common of all the types in

Table 1. Shows age and gender distribution of the studied subjects.

\begin{tabular}{cccccccc}
\hline & \multicolumn{3}{c}{ Male } & \multicolumn{3}{c}{ Female } & \multicolumn{3}{c}{ Total } \\
\cline { 2 - 7 } Age (yr) & $\mathbf{n}$ & \% & $\mathbf{n}$ & $\mathbf{\%}$ & $\mathbf{n}$ & $\%$ \\
\hline $10-20$ & 0 & 0 & 14 & 41 & 14 & 35 \\
$21-30$ & 5 & 83 & 14 & 41 & 19 & 47.5 \\
$31-40$ & 0 & 0 & 4 & 12 & 4 & 10 \\
$41-50$ & 1 & 17 & 2 & 6 & 3 & 7.5 \\
\hline
\end{tabular}

Table 2. Shows SCA compression on MR Angio of thoracic outlet in patients presenting with neurogenic thoracic outlet syndrome.

\begin{tabular}{ccccccc}
\hline $\begin{array}{c}\text { Neurogenic thoracic } \\
\text { outlet syndrome }\end{array}$ & $\begin{array}{c}\text { Subclavian artery } \\
\text { (SCA)compression }\end{array}$ & Right SCA compression & Left SCA compression \\
\hline & $\mathrm{n}$ & $\%$ & $\mathrm{n}$ & $\%$ & $\mathrm{n}$ & $\%$ \\
& 14 & 36 & 3 & 21 & 11 \\
\hline
\end{tabular}


all series [9]. In our study, 97\% patients had neurogenic TOS and 3\% vascular TOS. Similar results were found by Sanders R J et al. [10] in their study.

Provocation tests are well described in literature [11] [12] and reproduce the physiological mechanisms that may affect the neurovascular bundles in the thoracic outlet. These tests are purported to help delineate the possible level compression of neurovascular structures in either the scalene, costoclavicular or axillary interval. The classic provocation test has been reported to be unreliable and frequently positive (up to 90\%) for pulse obliteration in healthy patients [13]. Upper limb tension test was positive in 93\% patients in our study. Gilroy Meyer JS [14] observed similar results in their study. Positive physical findings after upper limb tension test (ULTT) were found in 98\% patients of TOS. Adson's test was positive in 73\% patients in our study. Engin Ucer, Burak Sade and colleagues (1984-1997) found similar results in their study, positive Adson's test was found in $75 \%$ patients and hyper abduction test in $25 \%$ patients [15].

Cervical rib occurs in less than $1 \%$ population and $70 \%$ are women. It is a predisposition to neurogenic TOS following neck trauma, most often whiplash injuries [16]. Symptomatic cervical rib usually produces symptoms of neurogenic TOS but a few will press against subclavian artery and result either in stenosis or aneurysm formation. In our study, 67\% patients had bilateral cervical rib. Among males, $40 \%$ and females $72 \%$ had bilateral cervical rib. Right side cervical rib is more common in females as compared to males. Antima Gupta, D.P Gupta, D.P Saxena, R.P Gupta (Dec 2012) observed similar results in their study. They found that bilateral cervical rib is more common in both males and females and left side cervical rib being more common in males in comparison to right side cervical rib in females [17].

Neuroelectrical studies are in inconsistently helpful, but may be useful in ruling out other more distal nerve entrapments [18]. In our study, most common electrophysiological abnormality was deranged sensory ulner nerve conduction velocity. Jasem Yosuf Al-Hashel et al. (2007-2010) found similar results in their study [19].

Clinical diagnosis is often difficult in TOS requiring the use of imaging procedure. Diagnosis is usually made by a combination of history, physical examination and one or more of diagnostic modalities. 36\% patients with neurogenic TOS had subclavian artery compression on MR Angio of the thoracic outlet after postural maneuver. Hale Ersoy et al. observed similar results in their study. They found that vascular component of TOS, which presented mainly with neurogenic or indeterminate symptoms or findings, was excluded in $61 \%$ subjects [20]-[23].

\section{Conclusion}

Neurogenic TOS represents the most common type of TOS and probably is the most detriment to the quality of life. Diagnosis of TOS is essentially based on history and clinical examination. Investigations can be helpful in confirming the suspected disgnosis. MRI is helpful in determining the presence of vascular compression and associated complications in TOS. Analysis of data from this prospective study clearly shows the importance of radiological investigations (MR Angio) in understanding the pathophysiology of TOS.

\section{References}

[1] Eisndrath, D.N. (1904) The Existence of Cervical Rib in Man. Am. Med, 8, 322-325.

[2] Tindall, S.C. and Youmans, J.R. (Eds.) (1990) Chronic Injuries of Peripheral Nerves by Entrapement. Neurological Surgery Third Edition, W.B. Saunders, Philadelphia, Vol. 4: 2511-2542.

[3] Astoy, E. (1996) Thoracic Outlet Compression Syndrome. Orthopedic Clinics of North America, 27, 265-303.

[4] Roos, D.B. (1982) The Place of Scalenectomy and First Rib Resection in Thoracic Outlet Syndrome. Surgery, 92, 1077-1085.

[5] Yaseen, Z. and Baram, A. (2014) Neurogenic Thoracic Outlet Syndrome Treatment by Supraclavicular Approach. Asian Cardiovascular and Thoracic Annals, 22, 193-196.

[6] Baker, D.M. and Lamerton, A.J. (1993) Outcome of Surgical Management of Thoracic Outlet Compression Syndrome in a District General Hospital. Annals of the Royal College of Surgeons of England, 75, 172-174.

[7] Ray, B.S., Hardy, R. and Parson, H. (1953) An Analysis of Findings in Fifty-Seven Operative Cases. Bulletin of the New York Academy of Medicine, 29, 60-70.

[8] Yaseen, Z. and Baram, A. (2013) Neurogenic Thoracic Outlet Syndrome Treatment by Supraclavicular Approach. Asian Cardiovascular and Thoracic Annals, published online 11 October 2013. http://dx.doi.org/10.1177/0218492313489840 
[9] Sandes, R.J., Hammond, S.L. and Rao, N.M. (2007) Diagnosis of Thoracic Outlet Syndrome. Journal of Vascular Surgery, 46, 601-604. http://dx.doi.org/10.1016/j.jvs.2007.04.050

[10] Sanders, R.J., Hammond, S.L. and Rao, N.M. (2007) Diagnosis of Thoracic Outlet Syndrome. Journal of Vascular Surgery, 46, 601-604.

[11] Elbaz, C. (1975) Thoraco-Brachial Outlet Syndrome. Phlebologie, 28, 397-418.

[12] Gillard, J., et al. (2001) Diagnostic Thoracic Outlet Syndrome: Contribution of Provocative Tests, USG, Electrophysiology and Helical CT in 48 Patients. Joint Bone Spine, 68, 416-424. http://dx.doi.org/10.1016/S1297-319X(01)00298-6

[13] Hachulla, E., Camilleri, G., Fournier, C. and Vinckier, L. (1990) Clinical, Flow Metric and Radiologic Study of Thoracic Outlet in 95 Healthy Subjects: Physiologic Limitations and Practical Impact. Revue De Medicine Interne, 11, 1924. http://dx.doi.org/10.1016/S0248-8663(05)80603-4

[14] GilroyMeyer, J.S. (1963) Compression of Subclavian Artery as a Cause of Ischemic Brachial Neuropathy. Brain, 86, 733-745. http://dx.doi.org/10.1093/brain/86.4.733

[15] Ucer, E., Sade, B., Acar, U., Guner, M. and Yraktar, S.E. (1999) Neurogenic Thoracic Outlet Syndrome Due to Compression at the Interscalene Triangle. Turkish Neurosurgery, 9, 137-143.

[16] Sanders, R.J. and Hammond, S.H. (2002) Management of Cervical Ribs and Anomalous First Ribs Causing Neurogenic Thoracic Outlet Syndrome. Journal of Vascular Surgery, 36, 51-56. http://dx.doi.org/10.1067/mva.2002.123750

[17] Gupta, A., Saxena, D.K. and Gupta, R.P. (2012) Cervical Rib: It’s Prevalence in Indian Population around Lucknow (UP) India. Journal of Anatomical Society of India, 61, 189-191. http://dx.doi.org/10.1016/S0003-2778(12)80030-X

[18] Youmans Jr., C.R. and Smiley, R.H. (1980) Thoracic Outlet Syndrome with Negative Adson’s and Hyperabduction Maneuvers. Vascular and Endovascular Surgery, 14, 318-329. http://dx.doi.org/10.1177/153857448001400504

[19] Al-Hashel, J.Y., El Shorbgy, A.A., Ahmed, S.F. and Elshereef, R.R. (2013) Early versus Late Surgical Treatment for Neurogenic Thoracic Outlet Syndrome ISRN. Neurology, 2013, 1-6.

[20] Ersoy, H., Steigner, M.L., Coyner, K.B., Gerhard-Herman, M.D., Rybicki, F.J., Bueno, R. and Nguyen, L.L. (2012) Vascular Thoracic Outlet Syndrome: Protocol Design and Diagnostic Value of Contrast Enhanced 3D MR Angiography and Equilibrium Phase Imaging on 1.5 and 3 T MRI Scanner. American Journal of Roentgenology, 198, 11801187. http://dx.doi.org/10.2214/AJR.11.6417

[21] Becker, F. and Terriat, B. (1999) Thoracic Outlet Syndrome: The Viewpoint of the Angiologist. La Revue de Médecine Interne, 20, 487S-493S.

[22] Fecheter, J.D. and Kuscner, S.H. (1993) The Thoracic Outlet Syndrome. Orthopedics, 16, 1243-1251.

[23] Ault, J. and Suutala, K. (1998) Thoracic Outlet Syndrome. Journal of Manual \& Manipulative Therapy, 6, 118-129. http://dx.doi.org/10.1179/jmt.1998.6.3.118

\section{Submit or recommend next manuscript to SCIRP and we will provide best service for you:}

Accepting pre-submission inquiries through Email, Facebook, Linkedin, Twitter, etc

A wide selection of journals (inclusive of 9 subjects, more than 200 journals)

Providing a 24-hour high-quality service

User-friendly online submission system

Fair and swift peer-review system

Efficient typesetting and proofreading procedure

Display of the result of downloads and visits, as well as the number of cited articles

Maximum dissemination of your research work

Submit your manuscript at: http://papersubmission.scirp.org/ 